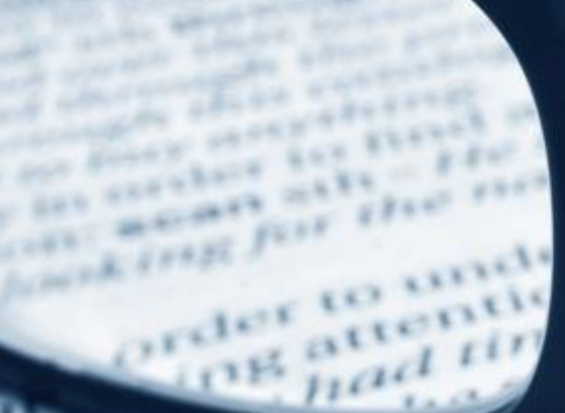

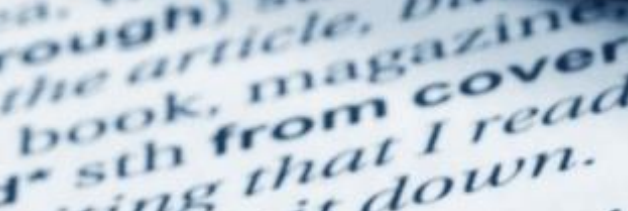

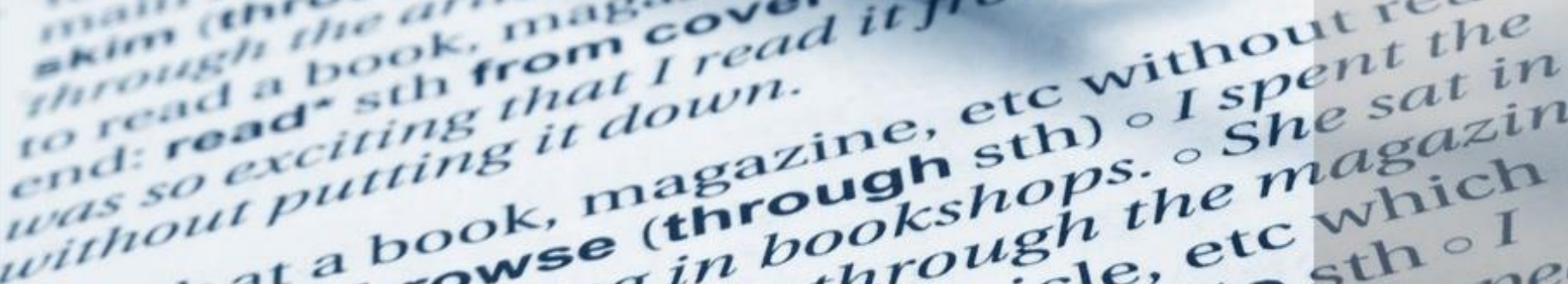

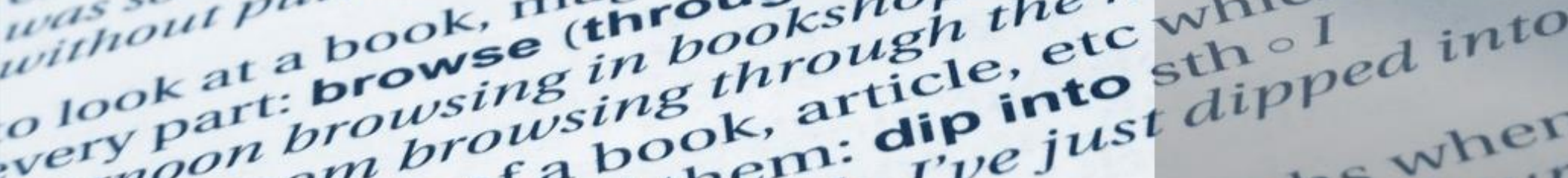
very pon brow browsing $\mathrm{k}$, arl dip into just dippea frem room of a bo them: ive just ons when

\title{
What is Discourse Analysis (DA)?
}

Ribut Wahyudi - Discourse Analysis Class UIN MALIKI Malang [21 Feb 2013], Email: ribut@bsi.uin-malang.ac.id 


\section{What is DA?}

- The definition for DA varies according to its inter-disciplinary natures. The scopes of DA range from textually-oriented views which mostly concentrates on language features of texts to more socially oriented views which examines the text in relation to its social and cultural setting (Paltridge, 2006). See Yan \& Sun (2010) on the definition of discourse from different perspectives. 


\section{When was DA firstly introduced?}

- The term was firstly proposed by Zellig Harris (1952). He was interested in: the examination of language beyond the level of sentence and the relationship between linguistic and non-linguistic behavior.

"connected discourse occurs within a particular situation_whether of a person speaking, or of a conversation, or of someone sitting down occasionally over periods of months to write a particular kind of book in a particular literary or scientific tradition" (Harris, 1952, p.3). 
The relation between language and context

- Context determines the meaning of language. E.g. the runway is full at the moment might be understood as the impossibility to land the plane, or merely the explanation why the plane is late landing. (your own example???) 


\section{DA and Pragmatic}

- DA and Pragmatic have intersecting domains. Pragmatics is interested in what people mean by what they say, rather than the most literal sense, contrasted to Semantics. Pragmatic view of DA, the consideration of the ways in which people mean more than what they say in spoken and written discourse, is explained in this course. 


\section{The discourse structure of text}

- One of discourse analyst's interests is how people structure what they first, next and so on in conversation or in writing.

e.g. - "Dear Dr. Paltridge,--Greeting from a hot and sizzling Tokyo".

- "Hello Mister, DVD or Hello Mister Louis Vuitton" along the street of Shanghai. (your own example???) 


\section{Cultural ways of speaking and}

\section{writing}

- the language use by particular cultural groups, ethnography of communication (Hymes, 1964). He considered aspects of speech events such as who is speaking to whom, about what, for what purpose, where and when, and how these impact on how we say and do things in culture specific settings. e.g. the ritual of please and thank in Australia. (your own example???) 


\section{Communicative Competence (CC)}

\section{and discourse}

- CC (Hymes, 1972) is an important part of ethnography of communication. It involves not only knowing a language (grammar), but also what to say to whom, and how to say and respond it appropriately in a particular situation.

- CC comprises of: grammatical, sociolinguistic, discourse and strategic competence. 


\section{Discursive Competence (DC)}

- Another way of looking at cultural ways of speaking and writing is through DC (Bhatia, 2004). It covers: textual competence, generic competence and social competence. Textual competence: the ability to produce and interpret contextually appropriate texts e.g. OIC, BB, gtg, Iol. Generic competence: the ability to respond both recurring and new communicative situations by constructing, interpreting, using and exploiting conventions associated with the use of particular text or genre. 


\section{Conts...}

- Social competence: how we use language to take part in social and institutional interactions in a way that enables us to express our social identity, within the constraints of the particular social situation and communicative situation. e.g. how we project our identities in different situations. 


\section{Different views of DA}

- Discourse as the social construction of reality. e.g.:

a. BBC Panorama interview with Princess Diana

b. The three scariest words in U.S. Industry: "The China Price". 


\section{Conts...}

- Cameron and Kulick (2003: 29).

"words in isolation are not the issue. It is in discourse-the use of language in specific context-that words acquire meaning. Whenever people argue about words, they are also arguing about the assumptions and values that have clustered about those words...the relationship with other words and to the discourse... discourse shifts and changes constantly, which is why arguments about words, and their meanings are never settled once for all" 


\section{Discourse and socially situated}

identities

- Discourse involves characteristic ways of acting, interacting, feeling and characteristic ways of showing emotion, gesturing, dressing and posturing.

e.g. Princess Diana in the Panorama Interview.

She knows not only how she is expected to speak in the particular place, time, but also how she can use body language to achieve the effects that she wants, as well as, the values, attitudes, beliefs, emotions it is appropriate (not) for her to express in this situation. 


\section{Discourse and performance}

- Discourse is like the performance of gendered identities, and are socially constructed rather than natural. People are who they are (because of (among other things) the way they talk not because who they (already) are (Cameron, 1999, p. 144).

- Discourse and performance also relates to the idea of performativity, speech act theory, (Austin). e.g. Once a priest says I now pronounce you man and wife, the couple have 'become' man and wife. 


\section{Discourse and Inter-textuality}

- All texts, whether they are spoken or written, make their meanings against the background of other texts and things that have been said on other occasions (Lemke, 1992). 
Differences between spoken and written discourse

- e.g. spoken: "if you invest in a rail facility, this implies that you are going to be committed for a long term" (L:7, G:13)

- e.g. written: "investment in a rail facility implies a long term commitment" (L:7, $\mathrm{G}: 3)$

NB: grammatical (function words) and lexical (content) words. (Halliday, 1989, p.61). 


\section{conts}

- grammatical intricacy in spoken discourse

- lexical density in spoken and written discourse

- nominalization in spoken and written discourse

- explicitness in spoken and written discourse

- contextualization in spoken and written discourse

- the spontaneous nature of spoken discourse

- repetition, hesitation and redundancy in spoken discourse 


\section{Conts...}

- a continuum of differences between spoken and written discourse.

\section{Reference:}

Paltridge, B. 2006. Discourse Analysis. London: Continuum. 


\section{Interpretation of discourse from different perspectives}

- Linguistic perspective: no consensus. e.g.

"a language unit beyond sentence" (Stubbs, 1983), "more than words in clauses" (Martin \& Rose, 2007), "a semantic unit, a unit not form but meaning" (Halliday \& Hassan, 1976)

* Anthropological Linguistic: the study of relations between language and culture, and the relations between cognition and language. 


\section{Conts...}

- Systemic Functional Linguistics (SFL): discourse is a dynamic multi-dimensional process. A text is the static product of that process (Halliday, 1994). Language is social semiotic. It is a semiotic system which stems from culture and society and conveys certain meaning in specific context. Language, on the basis of three contextual elements (field, tenor, mode), is multi-functional semantic system armed with potential significance. 


\section{Conts...}

- Cognitive Linguistics: discourse is composed of cognitive phenomena, and the principal approach is cognitive analysis. Thus interpreting discourse is a complex a complex and advanced course in which information is processed. 


\section{Conts...}

- Sociolinguistic perspective e.g. speaking (Hymes, 1972)

Non-linguistic perspectives:

- Philosophical studies e.g. M. Foucoult: Language, Power, Ideology etc

- Literary studies: literary discourse has a particular effect on the mind, refreshing and changing the reader's mental representation of the world.

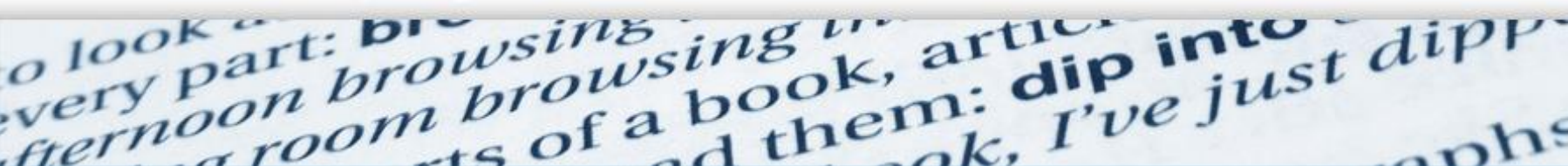




\section{Conts...}

- Interdisciplinary fields:

- Conversational Analysis (CA): discourse is actualized oral media of conversation. e.g. turn taking, repair, reference organization etc.

- Critical Discourse Analysis (CDA):

Wodak: discourse historical approach,

Vandjik: Cognitive approach 


\section{Conts...}

- Van Lueween: representation of social actors

- Fairclough: text, discourse practice and socio-cultural practice.

- Martin: positive discourse analysis etc. 


\section{References}

- Paltridge, B. (2006). Discourse Analysis. London: Continuum.

- Yang, W \& Sun, Y. (2010). Interpretation of discourse from different perspectives: A tentative reclassification and exploration of discourse analysis. The International Journal-Language Society and Culture, 31, 127-138. 